\title{
Pelatihan Pemanfaatan Limbah Akar Pohon Hutan Menjadi Hiasan
}

\author{
Soni Fajar Mahmud*1, John Suarlin ${ }^{2}$, Nur Budi Nugraha ${ }^{3}$ \\ 1,2 Program Studi Teknik Industri, Sekolah Tinggi Teknologi Dumai \\ 3 Program Studi Teknik Informatika, Sekolah Tinggi Teknologi Dumai \\ *e-mail: sfajarmahmud@gmail.com, johnsuarlin@gmail.com, nurbudinugroho87@gmail.com
}

\begin{abstract}
Dumai City has a forest area that has many trees. People use the tree for various needs. Utilization that has not been maximized, makes a lot of waste material from tree roots wasted. So that creativity training is needed to utilize the waste of tree roots. The purpose of this service is to provide knowledge about the field of creativity in the utilization of tree root waste as an alternative material for making art/crafts/decoration items. The method used in this research is the method of observation and interview of the processing and creation of tree root waste as an alternative to making arts and crafts with the following stages: (1) material selection, (2) design, (3) embodiment, (4) finishing. The results of this service are carried out by observing carefully the results of making forest tree root crafts into decorative crafts. This service is intended to find out other possibilities for utilizing tree root waste as an alternative to other industrial materials. The process is carried out through the stages of material selection, shape design, and formation. Another process that strongly supports the results of the craft of tree root waste is the formation of certain parts. Through the identification of various working techniques, the use of tree root waste along with its properties and characteristics, it can be concluded that there is a possibility that tree root waste can be used as an alternative for making handicrafts
\end{abstract}

Keywords:Tree Root Waste, Crafts, Decoration

\begin{abstract}
Abstrak
Kota Dumai memiliki kawasan hutan yang banyak memiliki pohon. Masyarakat memanfaatkan pohon tersebut untuk bermacam macam kebutuhan. Pemanfaatan yang belum maksimal, menjadikan banyak bahan bahan sisa limbah akar pohon terbuang sia - sia. Sehingga diperlukan pelatihan kreatifitas untuk memanfaatkan limbah akar pohon tersebut. Tujuan pengabdian ini adalah untuk memberikan pengetahuan tentang bidang kreatifitas dalam pemanfaatan limbah akar pohon sebagai alternatif bahan pembuatan barang seni kerajinan/hiasan. Metode yang digunakan dalam penelitian ini adalah metode observasi dan wawancara proses pengolahan dan penciptaan seni kerajinan limbah akar pohon sebagai alternatif pembuatan seni kerajinan dengan tahapan sebagai berikut: (1) pemilihan bahan, (2) perancangan, (3) perwujudan, (4) finishing. Hasil pengabdian ini dilakukan dengan mengamati hasil secara seksama dari pembuatan kerajinan akar pohon hutan menjadi kerajinan berbentuk hiasan. Pengabdian ini dimaksudkan untuk mengetahui kemungkinan lain pemanfaatan limbah akar pohon dapat menjadi alternatif bahan industri lain. Proses dikerjakan melalui tahapan pemilihan bahan, perancangan bentuk, dan pembentukan. Proses lain yang sangat mendukung hasil bentuk kerajinan limbah akar pohon adalah pembentukan bagian-bagian tertentu, Melalui identifikasi berbagai macam teknik pengerjaan, pemakaian limbah akar pohon beserta sifat dan karakternya dapat disimpulkan bahwa ada kemungkinan limbah-limbah akar pohon dapat digunakan sebagai alternatif pembuatan kerajinan.
\end{abstract}

Kata kunci: Limbah Akar Pohon, Kerajinan, Hiasan

\section{PENDAHULUAN}

Kota Dumai memiliki kawasan hutan yang banyak memiliki pohon. Penduduk dumai memanfaatkan pohon tersebut untuk bermacam macam kebutuhan. Mulai dari digunakan untuk industri keluarga, industri mebel, industri kerajinan maupun untuk bahan ekspor ke luar negeri (Fitria, 2013). Pemanfaatan yang belum maksimal, menjadikan banyak bahan bahan sisa limbah akar pohon terbuang sia - sia. Limbah akar pohon adalah limbah sisa dari penebangan kayu yang terpaksa harus ditinggalkan di dalam tanah karena terdapat kesulitan-kesulitan dalam pengambilannya atau 
dianggap tidak dapat menghasilkan produk (output) yang bernilai tinggi dari segi (Wardana \& Misdiyanto, 2019). Limbah akar pohon yang ditinggalkan dan dibiarkan begitu saja di dalam tanah dapat menyebabkan permasalahan terhadap tanah (Nugraha, Julanos, \& Suarlin, 2020). Tanah akan menjadi tandus, kering, dan tidak dapat ditanami kembali. Seiring dengan banyaknya kebutuhan manusia akan kayu, termasuk kebutuhan bahan industri, tidak menutup kemungkinan akan menjadi suatu permasalah tersendiri bagi lahan-lahan perkebunan dan pertanian (Riskina, Saputra, Saputra, Riskina, \& Maya, 2017).

Limbah akar pohon yang terus meningkat tersebut disebabkan oleh terus berkembangnya tingkat konsumsi masyarakat terhadap kebutuhan kayu sebagai pemenuhan kebutuhan rumah tangga, tindakan penebangan kayu, illegal loging yang merajalela, dan sebagainya (Supariadi \& Insiwi Febriary, 2018). Penggunaan material kayu, sebagai bahan utama dalam industri mebel, mengakibatkan banyak limbah kayu yang dihasilkan, salah satunya adalah limbah akar pohon. Jika tidak dimanfaatkan, keberadaan limbah ini akan menjadi sampah organik yang dapat menggangu pencemaran lingkungan, keindahan alam, dan gangguan ekosistem (Amri, Husain, \& Rauf, 2020).

Limbah akar pohon memiliki kesan yang artistik, unik, dan keras, sehingga limbahnya sayang untuk dibuang percuma. Pemanfaatannya dapat dilakukan dengan cara daur ulang, yakni proses untuk menjadikan suatu bahan bekas menjadi bahan baru dengan tujuan mencegah adanya sampah (Sutarman, 2016). Padahal, sebenarnya sampah tersebut dapat menjadi sesuatu yang berguna, mengurangi penggunaan bahan baku yang baru, dan mengurangi kerusakan lahan jika dibandingkan dengan proses pembuatan bahan baru (Apriyanti, 2018). Pemanfaatan pengolahan limbah akar pohon dapat dilakukan untuk berbagai hal, misalnya dijadikan sebagai bahan alternatif pembuatan kerajinan atau dibentuk barang baru yang lebih menarik, seperti relief akar pohon atau furniture tergantung kepada kreatifitas dan proses pengerjaannya (Hartono \& Janu, 2013).

Pohon yang sudah berusia tua biasanya mempunyai akar yang banyak dan kuat. Akar pohon ini dapat dirangkai menjadi produk kerajinan yang unik dan bernuansa etnik (Juni, Lydia, Mutia, \& Purwandito, 2021). Pemanfaatan bahan alam limbah akar pohon ini dilakukan untuk berkarya seni sekaligus bermanfaat juga sebagai tindakan yang arif pada alam dan lingkungan. Manusia sebagai bagian dari alam seyogyanya ikut memelihara dan melestarikan bumi dan lingkungan sebagai tempat yang nyaman untuk kehidupan (Sutarman, 2016).

\section{METODE}

Metode yang digunakan dalam kegiatan pelatihan ini yaitu ceramah dan diskusi, bimbingan dan pelatihan (Alimudin, Yuliati, \& Nugraha, 2019). Metode ceramah dan diskusi digunakan untuk menyampaikan informasi yang berkaitan dengan jenis jenis limbah akar pohon dan manfaat yang bisa dihasilkan dari limbah tersebut. Selama kegiatan ceramah dan diskusi peserta akan dibekali modul pelatihan. Metode bimbingan dan pelatihan digunakan untuk menindaklanjuti dan mematangkan materi yang telah disampaikan dalam ceramah dan diskusi. Dengan praktek langsung yaitu membuat kerajinan hiasan dari limbah akar pohon. Pada praktek ini, tim pengabdian melakukan pendampingan dalam pembuatan hiasan. Untuk bahan dan alat sudah disediakan oleh tim pengabdian. Sehingga diharapkan setelah kegiatan ini masyarakat memiliki keahlian dalam memanfaatkan limbah akar pohon

Target Pelatihan pemanfaatan limbah akar pohon hutan menjadi hiasan untuk memberikan skill atau ketrampilan ke karang taruna tunas karya kelurahan Kampung Baru Kecamatan Bukit Kapur dalam memanfaatkan limbah akar pohon yang banyak tidak digunakan lagi oleh masyarakat. 


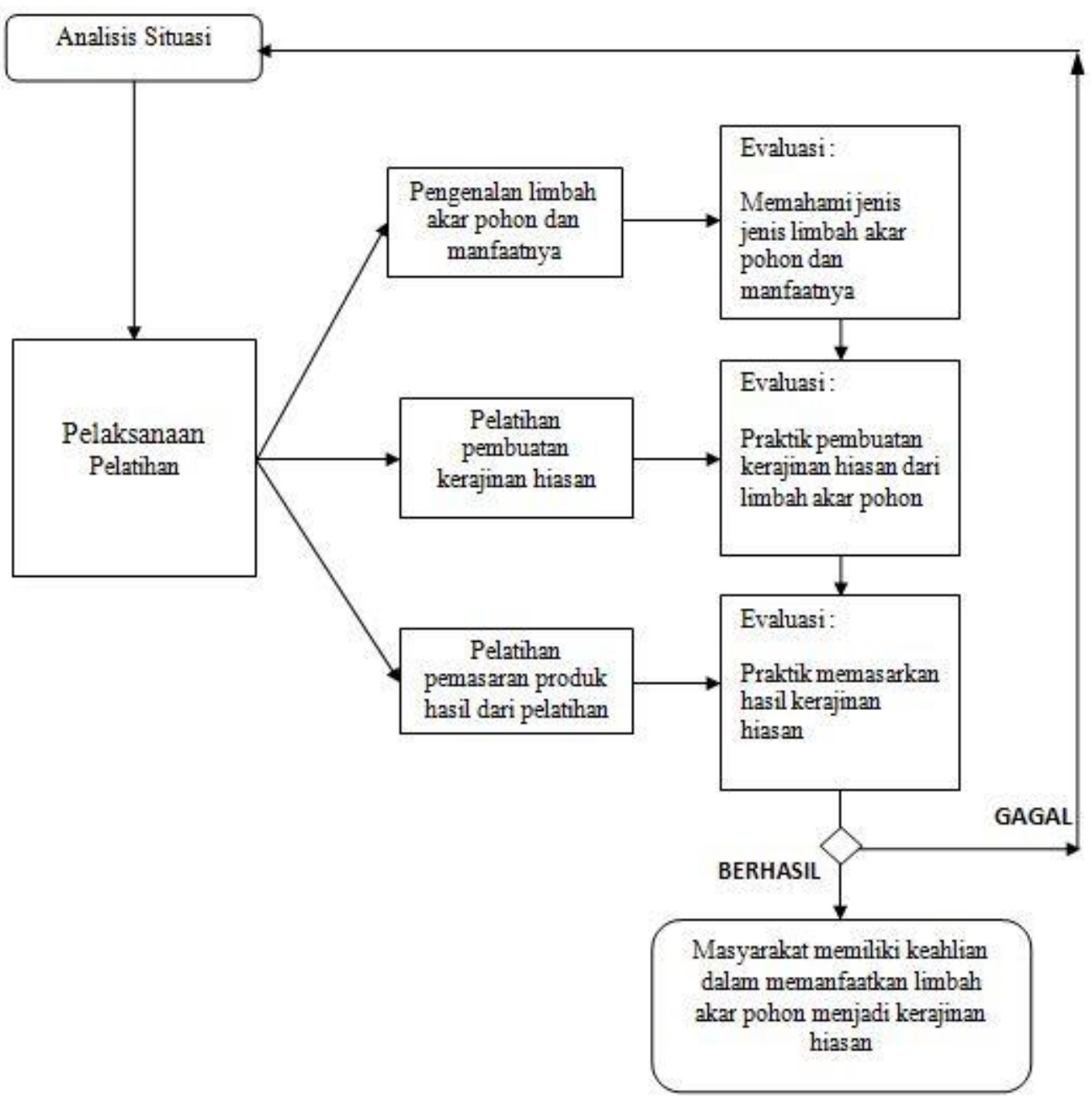

Gambar 1. Rancangan Evaluasi

\section{HASIL DAN PEMBAHASAN}

Kegiatan pengabdian pada masyarakat ini dilaksanakan selama dua hari yaitu pada hari Sabtu-Minggu tanggal 27-28 Maret 2021 kelurahan Kampung Baru Kecamatan Bukit Kapur dan dihadiri oleh seluruh karang taruna tunas karya. Pelatihan ini dibuka langsung oleh bapak Junaidi selaku lurah Kampung Baru. Bapak junaidi menyampaikan motivasi kepada para pemuda pemudi karang taruna agar bisa memanfaatkan waktu dengan meningkatkan ketrampilan mereka. Kegiatan hari pertama, materi disampaikan oleh Bapak John Suarlin, MM yang membahas tentang pengenalan pengetahuan dasar materi limbah akar pohon. Dalam sesi ini dosen memberikan informasi mengenai pemanfaatan limbah akar pohon yang mudah didapatkan di hutan yang ada di Kota Dumai. Selain itu pemateri juga memperkenalkan jenis jenis limbah akar pohon mana yang bisa digunakan untuk membuat kerajinan serta memberikan contoh produk yang bisa dihasilkan dari limbah akar pohon.

Materi kedua disampaikan oleh bapak Soni Fajar Mahmud, M.Si. Pada sesi ini, pemateri lebih fokus memberikan materi tentang perbedaan dari masing masing limbah akar pohon yang akan digunakan. Peserta diberikan contoh limbah akar pohon melalui 
slide powerpoint yang sudah disediakan oleh pemateri. Peserta sangat antusias dalam memerhatikan materi yang disampaikan oleh dosen. Ternyata selama ini mereka kurang mengetahui bahwa akar akar pohon di hutan bisa dimanfaatkan menjadi kerajinan yang mempunyai nilai jual sehingga bisa menjadi pemasukan tersendiri buat para peserta.

Pada hari kedua, team pengabdian melaksanakan praktek secara langsung serta membawa beberapa alat yang diperlukan dalam proses pelatihan yang meliputi amplas kasar dan halus, cat kayu waterbased, clear waterbased dan lem alteko. Selain itu peserta juga diajak untuk mencari limbah akar pohon yang akan digunakan untuk praktek membuat kerajinan.
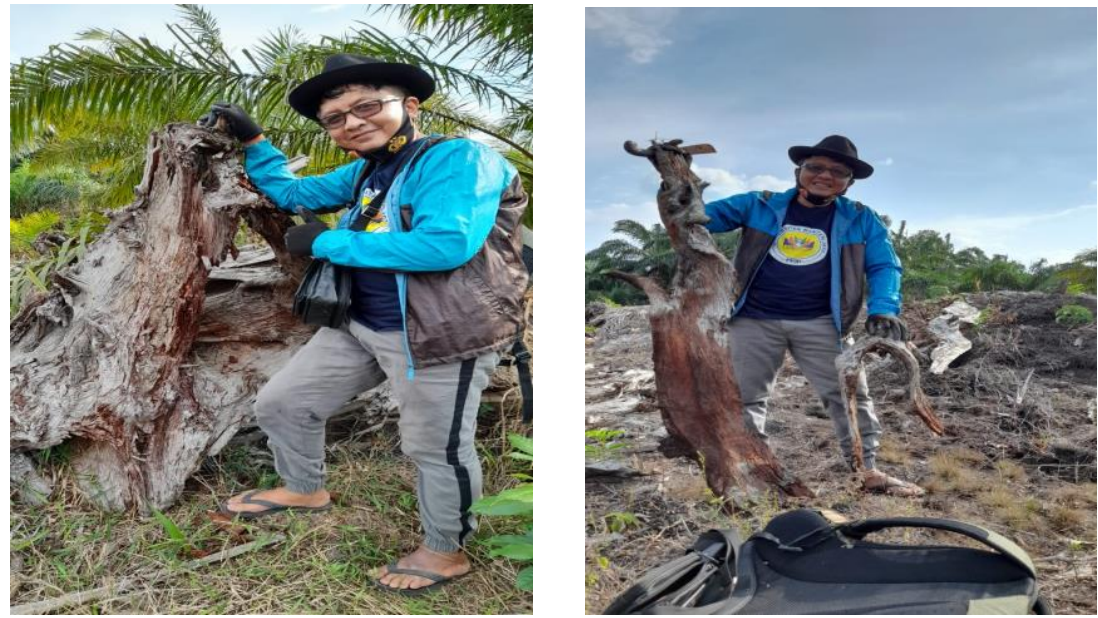

Gambar 2. Pencarian Limbah Akar Pohon Hutan

Team pengabdian STT Dumai mengajari secara langsung praktek untuk membuat kerajinan dari limbah akar pohon dengan alat dan bahan yang sudah disediakan sebelumnya. Mulai dari memilih akar pohon yan akan digunakan, mengaluskan dengan amplas sampai proses pengecatan dengan cat waterbased agar kelihatan mengkilat. Para peserta sangat antusias dalam mengikuti kegiatan praktek ini.
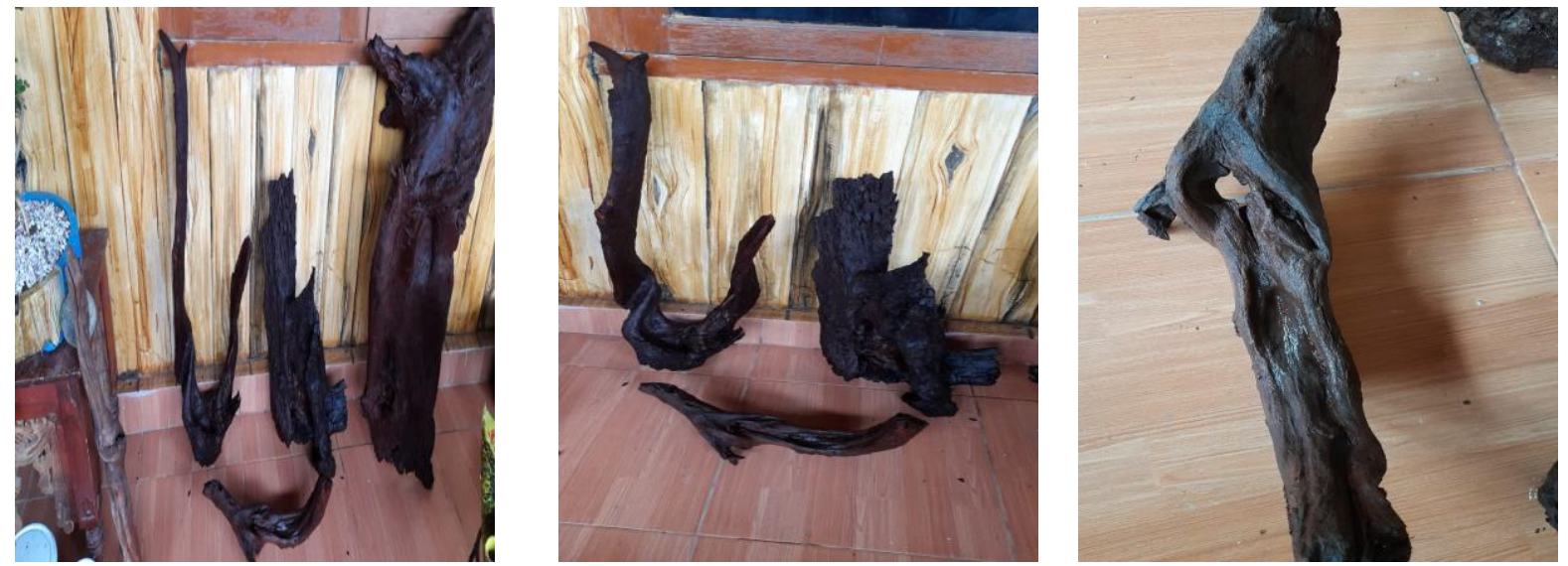

Gambar 3. Limbah Akar Pohon Yang Sudah Dicat

Secara umum kegiatan pengabdian ini berjalan lancar, dimulai dari kegiatan survei pendahuluan, pelaksanaan kegiatan pengabdian, sampai kepada penyusunan laporan. Berdasarkan diskusi yang diselenggarakan diperoleh kesimpulan bahwa para peserta pengabdian tersebut merasa senang dan puas. Hal ini terbukti dengan adanya 
permintaan dari para peserta agar kegiatan pengabdian ini tidak hanya diselenggarakan satu kali tetap harus berkelanjutan, mengingat pentingnya pembelajaran dan pengenalan manfaat limbah akar pohon hutan yang mempunyai nilai jual setelah diubah menjadi kerajinan atau hiasan.

Melalui pengabdian yang berkelanjutan akan terjalin hubungan kerjasama antara Sekolah Tinggi Teknologi Dumai dengan karang taruna tunas karya kelurahan kampung baru. Hubungan kerjasama dalam hal pengembangan jiwa kewirausahaan bagi karang taruna sehingga program pengabdian masyarakat dapat berjalan maksimal yang menjadi salah satu kewajiban dosen Sekolah Tinggi Teknologi Dumai. Tingginya antusiasme peserta ditandai dengan banyaknya pertanyaan dan tingginya perhatian dari peserta sejak pengabdian dimulai hingga berakhir. Peserta pengabdian juga meminta agar pelatihan ini dapat dilanjutkan pada tahun mendatang dan disediakan kesempatan bagi para peserta untuk konsultasi lebih mendalam untuk semua materi pelatihan.

Faktor-faktor yang mendukung pelaksanaan pengabdian sehingga dapat terlaksana dengan lancar adalah tingginya antusiasme peserta pengabdian karang taruna tunas karya untuk mengikuti pelatihan ini, Manfaat yang besar atas tema pengabdian memberikan pengetahuan dan ketrampilan yang baru kepada pemuda karang taruna dalam memanfaatkan barang yang tidak terpakai. Selain faktor pendukung, ada pula faktor penghambat yang mengakibatkan kegiatan pengabdian ini tidak mampu mencapai tujuan secara maksimal, yaitu waktu pengabdian hanya dua hari dan singkat mengakibatkan peserta masih banyak ingin mendalami tentang pembuatan kerajinan atau hiasan dari limbah akar pohon hutan kurang maksimal dan Koordinasi antar peserta pegabdian belum bisa berjalan dengan sempurna karena perbedaan kegiatan dan kepentingan masing-masing untuk memiliki hari yang sama untuk mengikuti kegiatanpengabdian.

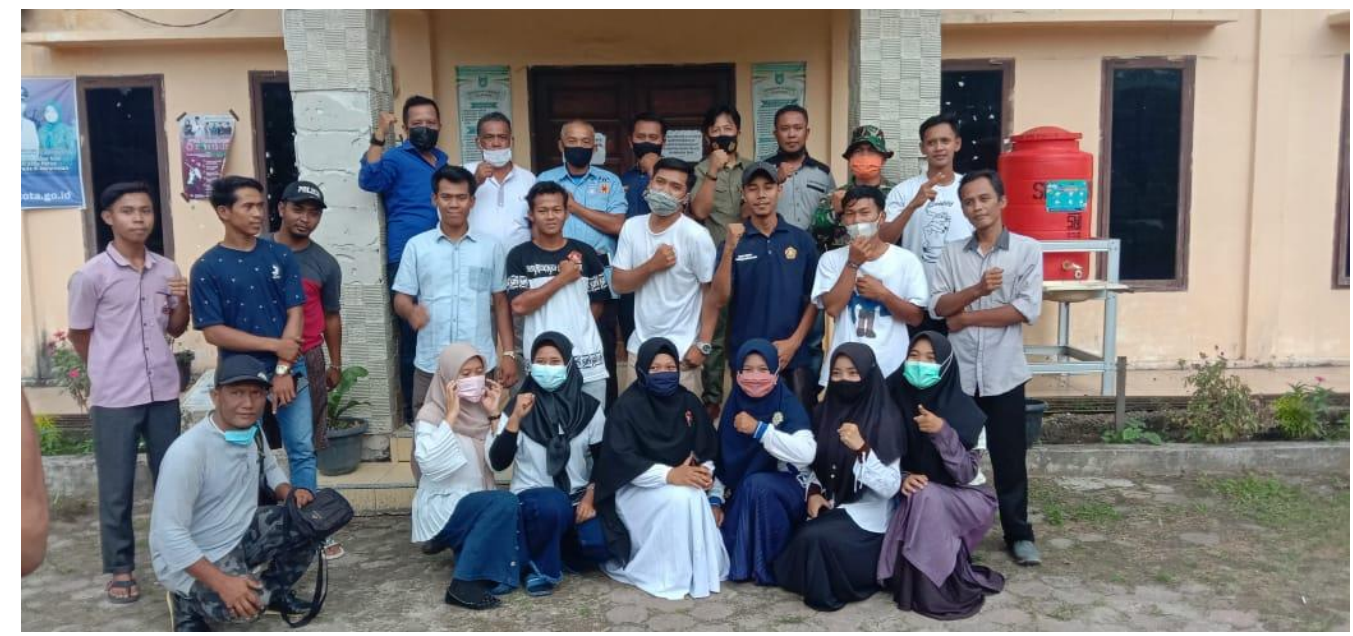

Gambar 4. Peserta Pengabdian Karang Taruna Tunas Karya

Gambar 4 menjelaskan tentang acara setelah kegiatan pengabdian selesai. Dimana peserta pengabdian mengajak kepada team pengabdian STT Dumai untuk berfoto bersama dalam rangka sebagai dokumentasi dan kenang-kenangan buat pemuda karang taruna Tunas Karya.

\section{KESIMPULAN}

Berdasarkan uraian pelaksanaan kegiatan pengabdian ini, maka dapat ditarik kesimpulan sebagai berikut:

1. Para peserta merasa memperoleh wawasan baru tentang manfaat dan ketrampilan yang 
diperoleh dari limbah akar pohon yang selama ini mereka tidak tahu dan membuat menjadi sebuah kerajinan atau hiasan yang mempunyai nilai jual.

2. Peserta pengabdian sangat merasa senang dan puas dengan kegiatan pengabdian dan meminta agar pengabdian serupa dilaksanakan berkesinambungan mengingat pelatihan kewirausahaan pemanfaatan limbah akar pohon ini sangat membantu pemuda karang taruna dalam mendapatkan penghasilan yang dapat diperoleh dari hasil kerajinan atau hiasan limbah akar pohon.

\section{UCAPAN TERIMA KASIH}

Penulis mengucapkan terima kasih kepada Ketua Sekolah Tinggi Tinggi Dumai dan Ketua Lembaga Penelitian dan Pengabdian Kepada Masyarakat Sekolah Tinggi Tinggi Dumai yang telah memberikan bantuan dana dalam penyelenggaraan pengabdian masyarakat ini. Selain itu, penulis juga mengucapkan terima kasih kepada panitia dan peserta pelatihan sehingga acara ini dapat terlaksana dengan baik dan lancar.

\section{DAFTAR PUSTAKA}

Alimudin, E., Yuliati, T., \& Nugraha, N. B. (2019). Pelatihan Media Pembelajaran dengan Ms. Office Power Point bagi Guru SMA IT Plus BAZMA Brilliant Dumai. Madani : Indonesian Journal of Civil Society, 1(1), 11-16. https://doi.org/10.35970/madani.v1i1.28

Amri, A. L., Husain, M. S., \& Rauf, B. A. (2020). PKM pemanfaatan akar dan tangkai kayu menjadi bonsai imitasi pada warga binaan Lapas Narkotika Bollangi. Seminar Nasional Pengabdian ..., 678-682. Retrieved from https://ojs.unm.ac.id/semnaslpm/article/download/11932/7036

Apriyanti, I. R. (2018). Studi potensi pemanfaatan limbah serat batok siwalan (Borassus flabellifer L.) sebagai bahan baku kerajinan lokal (Benang) Gresik. Jurnal Teknologia, 1(1), 79-86. Retrieved from https://aperti.ejournal.id/teknologia/article/view/10

Fitria. (2013). LIMBAH AKAR POHON SEBAGAI ALTERNATIF PEMBUATAN SENI KERAJINAN BENTUK-BENTUK BINATANG. Journal of Chemical Information and Modeling, 53(9), 1689-1699.

Hartono, A., \& Janu, P. B. H. (2013). Pelatihan Pemanfaatan Limbah Kulit Pisang Sebagai Bahan Dasar Pembuatan Kerupuk. Seri Pengabdian Masyarakat 2013, Jurnal Inovasi Dan Kewirausahaan, 2(3), 198-203.

Juni, N. J., Lydia, E. N., Mutia, E., \& Purwandito, M. (2021). Global Science Society : Jurnal Ilmiah Pengabdian Kepada Masyarakat, 3(1), 81-87.

Nugraha, N. B., Julanos, J., \& Suarlin, J. (2020). Peningkatan Kemampuan Berbahasa Inggris Bagi Siswa SMP. Madani : Indonesian Journal of Civil Society, 2(2), 2227. https://doi.org/10.35970/madani.v2i2.206

Riskina, E., Saputra, D., Saputra, F., Riskina, E., \& Maya, A. (2017). Pelatihan Pembuatan Bonsai "Bokabu" dari Oleana Syzygium Khas Borobudur untuk Peningkatan Nilai Ekonomi Tanaman. Urecol, 119-124. Retrieved from http://journal.ummgl.ac.id/index.php/urecol/article/view/736

Supariadi, \& Insiwi Febriary. (2018). Modifikasi Pola Pikir Historis Masyarakat di Sentra Industri Akar Jati. Cakra Wisata, 19(2), 23-34. 
Sutarman, I. W. (2016). Pemanfaatan Limbah Industri Pengolahan Kayu di Kota Denpasar (Studi Kasus pada CV Aditya). Jurnal PASTI, 10(1), 15-22. Retrieved from https://publikasi.mercubuana.ac.id/index.php/pasti/article/view/668

Wardana, L. A. W. A., \& Misdiyanto, M. (2019). Pkm Kelompok Industri Kreatif "Pengrajin Limbah Kayu" Untuk Memperkuat Ekonomi Lokal Di Kecamatan Mayangan Kota Probolinggo. Jurnal Komunitas : Jurnal Pengabdian Kepada Masyarakat, 2(1), 71-77. https://doi.org/10.31334/jks.v2i2.472 